\title{
Features of the Genetic Structure of the Earthworms Aporrectodea (Superspecies) Caliginosa (Oligochaeta: Lumbricidae) Complex in Ukraine
}

\author{
S. V. Mezhzherin ${ }^{a}$, R. P. Vlasenko ${ }^{b}$, and A. V. Garbar ${ }^{b}$ \\ ${ }^{a}$ Shmalgauzen Institute of Zoology, National Academy of Sciences of Ukraine, Kiev \\ e-mail:mezh@izan.kiev.ua \\ ${ }^{b}$ Ivan Franko State University, Zhitomir \\ Received January 15, 2008
}

\begin{abstract}
An investigation of the genetic structure of the Aporrectodea caliginosa - A. trapezoids diploidpolyploid complex of earthworms found in the Ukraine is performed by means of biochemical genetic marking with respect to six loci (Aat, Es-1, -2, -3, and -4, and $M d h$ ) and karyotyping. All 646 individuals from 21 samples are analyzed at the biochemical gene level and karyotype samples are obtained from 70 specimens. As a result, diploid amphimictic $A$. caliginosa individuals $(2 n=36)$, which form panmictic populations, and triploid $(2 n=54)$ A. trapezoides individuals, represented by 19 hypothetical clones discovered in the course of an analysis of 157 specimens, are clearly differentiated. A clear trend towards dominance of the triploid forms in the steppe zone of Ukraine is discovered. Here they represent roughly $70 \%$ as against $12 \%$ of all $A$. (superspecies) caliginosa individuals in the northern forest regions. Based on the stated nature of the heterozygosity of the loci studied and the behavior of the chromosomes in meiosis, it may be claimed that the cloned forms are allotriploids, formed as a result of hybridization of a series of related forms, which, judging from the allelic pools, does not include amphimictic species that now inhabit the territory of Ukraine. That is, either the apomictic clones of $A$. trapezoides lack a local origin and their appearance among the fauna of Ukraine is a consequence of settlement in arid steppe regions that are unfavorable for earthworms or, on the other hand, amphimictic $A$. caliginosa is an invasive species.
\end{abstract}

DOI: $10.3103 / \mathrm{S} 0095452708040075$

\section{INTRODUCTION}

However paradoxical it may seem, a trend has become apparent in recent decades that focuses on the examination of the systematics, not of rare exotic species, but of widespread, large-scale and, it would seem, the most highly studied animals, many of which have already long been model subjects in a number of experimental investigations. The cause for such a change in focus can be found in the gradual transition from a topological to an evolutionary conception of a species, from simple discrimination (basically, enumeration) of morphological forms to the examination of a species as an evolutionary trajectory. One such group of animals is the species complex of the earthworms, which in Russian zoology is usually interpreted as the unified species Aporrectodea caliginosa s. lato [1]. This is one of the most abundant species complexes of ground animals in the open landscape of Ukraine, a circumstance that is related to the widespread dissemination of the animal and its large population. Among the features of A. caliginosa s. lato which should be noted are the presence of a polyploid parthenogenetic form. In recent years, this form has been combined into a separate species $A$. trapezoides, though the domestic school of systematics is far more conservative, and its members have adhered to a broad conception, according to which polyploid individuals are considered to constitute only a separate form [1], or subspecies A. c. trapezoides [2].

Genetic studies of earthworms undertaken as early as the 1950s [3] demonstrated that the modern species of earthworms are amphidiploids with chromosome set $2 n=36-40$. According to these studies, some of these species are capable of forming a series of even- and odd-numbered polyploid forms, which correspondingly reproduce by means of amphi- or apomixis (parthenogenesis). The application of methods of biochemical gene marking has demonstrated that the polyploid forms of earthworms form a set of clones and are polyphyletic [4-15]. Even in an insignificantly small fraction of the habitat, the number of these forms may be counted in the tens and even hundreds of thousands, depending on the particular species. It also remains open to question whether an auto-polyploid origin for some strain of earthworms is possible [2]. Studies of Mediterranean triploid populations of A. caliginosa [8] have established the absence of constant heterozygosity, a result which is apparent from the electrophoretic spectra, which serves as the only proof of auto-polyploidy in earthworms. 


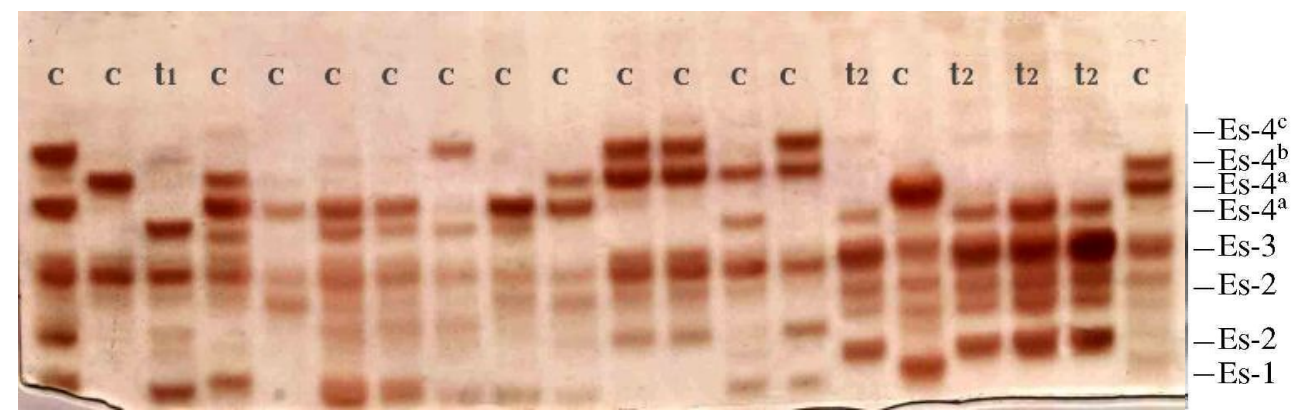

Fig. 1. Variability of nonspecific esterases: $\mathrm{c}-A$. caliginosa $; \mathrm{t}-$ A. trapezoides (1 - Clone XIV, 2 - Clone IX).

It should be noted that, despite the attraction of earthworms as subjects of evolutionary-genetic research, studies of genetic structure have been limited to individual regions, for Europe, in particular, such studies have been limited to Scandinavia. Meanwhile, earthworms in the territory of Ukraine have not been the focus of genetic studies, and not only at the gene, but even at the chromosome and genome levels. However, in view of the diversity of natural conditions, it is obvious that in Ukraine the fauna of earthworms must be among the richest in the Palearctic. Therefore, the objective of the present study was to investigate the genetic structure of earthworms in the territory of Ukraine by means of biochemical gene marking and karyological analysis, ultimately for the purpose of constructing a comparative description of diploid (bisexual) and polyploid (unisexual) forms.

\section{MATERIALS AND METHODS}

In order to perform the genetic marking, samples of the earthworks $A$. caliginosa s. lato that encompass most of the territory of Ukraine were studied. A total of 21 samples which included 646 individuals obtained from the following locations were analyzed: Nikolaevka, Simferopol District (Crimea Autonomous Republic) (14 specimens); Kramatorsk City, Donets Region (20 specimens); Zhitomir, Zhitomir Region (streets, courtyards, 216 specimens); Romanov PGG, Zhitomir Region (55 specimens); Serby Village, Emel'chin District (8 specimens); Eme'lyanovka, Korosten District (14 specimens); Starye Velidnyki, Ovruch District (8 specimens); Kiev, Kiev Region (Fomin Botanic Gardens, 14 specimens; Goloseevo, 8 specimens); Rusanov

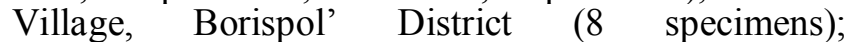
Kozhukhovka, Vasil'kov District (23 specimens); Mriya Village, Kiev-Svyatoshin District (14 specimens); Karoliena-Bugas Village, Ovidiopol' District, Odessa Region (8 specimens); Vilkovo Village, Izmail' District (54 specimens); Sumy City, Sumy Region (10 specimens); Pechishche Village, Sumy District (13 specimens); Nezhin City, Chernigov Region (25 specimens); Novyy Bykov Village, Bobrovits Dis-tict (6 specimens); Galitsa City, Nezhin District (40 specimens); Grigorovka Village, Kanev District,
Cherkasska Region (46 specimens); Makishino Village, Gorodnyan District, Chernigov Region (19 specimens); and Skadovska City, Kherson Region (23 specimens). The electrophoretic variability of the spectra of three enzymes which are encoded by six loci was studied by means of electrophoresis in polyacrylamide gel using tris-EDTA-borate $(\mathrm{pH} 8.5)$ from the system of buffers of [16] in tissue extracts taken from the tail of the body of the animal.

Chromosomal specimens were obtained by a dry-air method with preliminary colchicinization of the animals, a technique that has been used in studying the karyotypes of invertebrates [18[, including earthworms [2]. Colchicine $(0.02 \%$ solution) was injected into the animals $24 \mathrm{~h}$ prior to preparation. To produce the karyological preparations, the sperm sacs were fixated in an alcohol-acetic fixative $(3: 1)$ following preliminary hypotonic treatment in distilled water $(60 \mathrm{~min})$. A cell suspension was prepared from fragments of the gonad and the suspension extracted and deposited on dry microscope slides that had been heated to $60^{\circ} \mathrm{C}$. The preparations were then dried and stained with azureeosin that had been prepared in a phosphate buffer (pH 6.8) in accordance with the Romanovskii technique.

\section{RESULTS}

Electrophoretic Variability. Nonspecific esterases. Nonspecific esterases appeared in several zones of activity, most likely due to the expression of four loci (Fig. 1), each of which was duplicated. The effects of the gene dose, which sharply reduced the intensity of the fraction corresponding to one of the alleles, favors the latter circumstance. Moreover, the loci $E s-1, E s-2$, and $E s-3$ exhibit so high a level of polymorphism as to make it extremely difficult to arrive at their allelic interpretation, particularly in light of the gene dose. Therefore, the locus $E s-4$, which encodes the most active hydrolases and exhibits a moderate level of polymorphism, is the locus which is of practical interest. Obviously, it is precisely the locus (which is represented by a series of three alleles) which has previously been used in an analysis of the North American species $A$. tuberculata [19]. The empirical distribution of the genotypes 
(a)

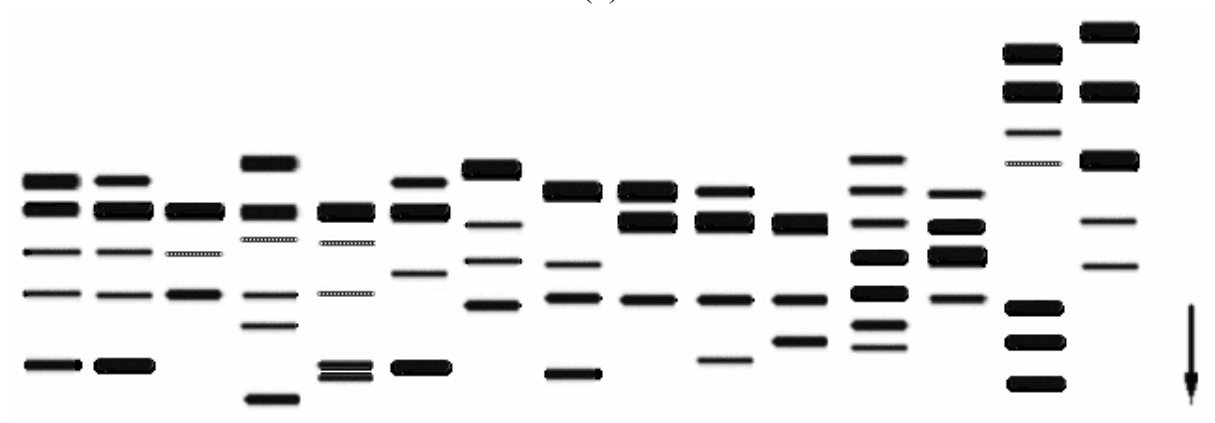

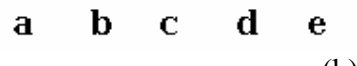

(b)

$\begin{array}{lllll}\mathbf{k} & \mathbf{l} & \mathbf{m} & \mathbf{n} & \mathbf{o}\end{array}$

(c)

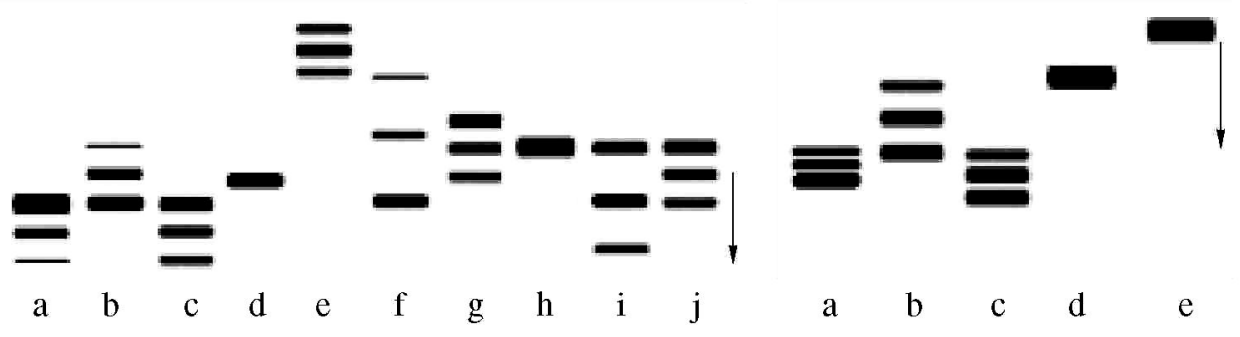

Fig. 2. Electrophoretic spectra of $A$. trapezoides: a - nonspecific esterase ( $-1,-2,-3,-4) ; \mathrm{b}$ - aspartate aminotransferase (Aat); c malate dehydrogenase $(M d h)$.

of the $E s-4$ locus in the largest sample of earthworms that we had collected, i.e., in the city of Zhitomir, demonstrated in the course of a single season good agreement with the theoretical distribution. The latter was obtained on the basis of the Hardy-Weinberg formula and is usually observed in amphimictic mammals:

$$
\begin{aligned}
& \&-4^{\mathrm{aa}} \\
& \&-4^{\mathrm{ab}} \\
& E s-4^{b b} \\
& E s-4^{C C} \\
& E s-4^{a c} \\
& E s-4^{b c} \\
& \boldsymbol{X}^{2}
\end{aligned}
$$

In terms of the nature of the allozyme variation of the nonspecific esterases, above all, $E s-4$, the worms were clearly differentiated into forms that may be divided into two groups, on the one hand, individuals of the diploid species $A$. caliginosa, on the other hand, a series most likely of polyploid forms, possessing fixations of either sufficiently specific alleles or constant multiple heterozygosity (Fig. 2a), which in recent years has been considered a separate species $A$. trapezoides. If the hypothetical polyploid forms are represented by a series of individuals, the constancy of the spectra encoded by the loci of the nonspecific esterases and, especially, the highly variable loci $E s-1$ and $E s$-2, give every reason for assuming that they are all representatives of a single clone. In a number of cases, however, most often in northern populations, where isolated specimens that "deviate" in terms of spectra have been found, the interpretation of particular individuals as clones has not been formally substantiated.

An analysis of the geographic distribution of the incidence of alleles in study samples of the diploid species A. caliginosa s. str has not revealed any clear trends in the variability of alleles of the locus $E s-4$ on the territory of Ukraine. Moreover, in a number of cases geographically neighboring samples exhibited a degree of differentiation higher than geographically remote samples, and for this reason there is every basis for considering the amphimictic form as a separate species.

Aspartate aminotransferase. In the diploid form this enzyme is polymorphic. Three alleles, distributed in accordance with a model of random crossings, have been found. Moreover, even in the diploid individuals the heterozygotes always possess asymmetric spectra, which confirms the amphidiploid nature of the species. A total of eight types of Aat spectra were found in apomictic clonal forms that had been preliminarily determined with respect to nonspecific esterases (Fig. 2b). Variant $a$ is typical of most of the amphimic-tic worms.

Malate dehydrogenase. A constantly heterozygous type $a$ is encountered in the amphimictic form (Fig. 2c), while five different types of spectra that correspond formally to homo- or heterozygous genotypes, were found in the apomictic form. 
Genetic structure and diversity of clones of $A$. trapezoides

\begin{tabular}{|c|c|c|c|c|c|c|c|c|c|c|}
\hline \multirow{2}{*}{ Enzyme } & \multicolumn{10}{|c|}{ Clone } \\
\hline & I & II & III & IV & $\mathrm{V}$ & VI & VII & VIII & IX & $\mathrm{X}$ \\
\hline$E S$ & $\mathrm{a}$ & $\mathrm{c}$ & $\mathrm{f}$ & $\mathrm{h}$ & $\mathrm{i}$ & $\mathrm{j}$ & $\mathrm{k}$ & $\mathrm{a}$ & $\mathrm{b}$ & $\mathrm{e}$ \\
\hline Aat & $\mathrm{b}$ & $\mathrm{b}$ & $\mathrm{a}$ & $\mathrm{i}$ & $\mathrm{h}$ & $\mathrm{h}$ & $\mathrm{h}$ & $\mathrm{f}$ & $\mathrm{a}$ & $\mathrm{a}$ \\
\hline$M d h$ & $\mathrm{a}$ & b & $\mathrm{a}$ & $\mathrm{a}$ & $\mathrm{a}$ & $\mathrm{a}$ & $\mathrm{a}$ & $\mathrm{a}$ & $\mathrm{d}$ & $\mathrm{a}$ \\
\hline $\mathrm{n}$ & 38 & 25 & 3 & 32 & 9 & 8 & 5 & 11 & 8 & 4 \\
\hline $\mathrm{N}$ & 5 & 2 & 2 & 1 & 1 & 1 & 1 & 1 & 1 & 1 \\
\hline \multirow{2}{*}{ Enzyme } & \multicolumn{10}{|c|}{ Clone } \\
\hline & XI & XII & XIII & XIV & XV & XVI & XVII & XVIII & \multicolumn{2}{|c|}{$X X$} \\
\hline$E s$ & o & $\mathrm{m}$ & $\mathrm{n}$ & d & d & $\mathrm{f}$ & g & 1 & \multicolumn{2}{|c|}{$\mathrm{a}$} \\
\hline Aat & $\mathrm{a}$ & e & - & $\mathrm{a}$ & e & $\mathrm{c}$ & $\mathrm{a}$ & - & \multicolumn{2}{|c|}{ d } \\
\hline$M d h$ & $\mathrm{a}$ & e & $\mathrm{a}$ & $\mathrm{c}$ & - & $\mathrm{a}$ & - & e & \multicolumn{2}{|c|}{$\mathrm{a}$} \\
\hline $\mathrm{n}$ & 3 & 2 & 2 & 1 & 1 & 1 & 1 & 1 & \multicolumn{2}{|c|}{1} \\
\hline $\mathrm{N}$ & 1 & 1 & 1 & 1 & 1 & 1 & 1 & 1 & \multicolumn{2}{|c|}{1} \\
\hline
\end{tabular}

Note: Clones: I - Grigorovka, Emel'yanovka, Mriya, Nezhin, Rusanov; II - Donetsk, Kozhukhovka; III - Galitsa, Novyy Bykov; IV-VII, XIX - Vilkono; VIII - Nikolaevka; IX - Skadovska; X, XI - Makishino; XII, XVI-XVIII - Grigorovka; XIII - Starye Velidniki; XIV - Zhitomir; XV - Galitsa; XIX - Rusanov; $n$ - number of individuals of given clone; $N$, number of samples in which clone was found.

Diversity of $\boldsymbol{A}$. trapezoides clones. As a result of an analysis of the electrophoretic variability of the three enzymes encoded by the six loci, besides the amphimitic form A. caliginosa, which forms panmictic populations, 19 apomictic clones of $A$. trapezoides were also found (cf. table). These clones were discovered in 16 of the 21 study samples, moreover, their incidence varied between the samples, most of the clones being unique and encountered only at a particular site. On average, 1.3 clones were found per sample of $A$. (superspecies) caliginosa, moreover, the number in a sample varied from 0 to 5 . In 11 cases representatives of only a single clone were discovered.

A geographic analysis of the distribution of apomictic forms in samples of $A$. caliginosa s. lato confirms the increase in their representation in southern Ukraine. Thus, whereas the mean percentage of polyploids on the entire territory of Ukraine amounted to $24 \%$, in the samples from Crimea, Vilkovo, Skadovska, and Kramatorsk the percentage of polyploids reached $70 \pm 4.2 \%$, and in the northern regions of Zhitomir, Kiev, Chernigov, and Sumy regions, it fell to $12 \pm 2.6 \%$.

Karyotypic Structure. All the specimens identified at the level of gene markers as amphimictic A. caliginosa s. str individuals from which chromosome preparations of satisfactory quality had been obtained 1 (18 specimens) contained metaphase plates $2 n=36$. In meiosis 18 of them were observed to be bivalent (Fig. 3 ), which proves that they are diploid; this result is also in accord with the karyological description of this species [2].

CYTOLOGY AND GENETICS Vol. 42 No. 42008
Mitotic metaphases $3 n=54$ were discovered among representatives of five clones of $A$. trapezoides, that is: Clone I - Grigorovka, Emel'yanovka, Mriya, Rusanov; Clone VIII - Nikolaevka; Clone XIII - Bol'shie Velednikii; Clone XV - Galitsa; and Clone XX - Rusanov.

In meiosis, plates with varying number of elements were observed among the worms of Clone I, the actual number of elements in most cases exceeding the haploid chromosome number $(n=18-36)$. Besides bivalents, these plates each contained several polyvalents (predominantly trivalents) and a significant number of univalents (Fig. 4), which is characteristic of polyploid individuals [20]. The presence of a large number of univalents attests to the nonhomology of the three haploid sets forming the karyotype of this form. The karyotype most likely consists of two homologous sets whose chromosomes form normal bivalents in meiosis and a single partially homologous form. In addition, the homologous chromosomes of the third set participate in the formation of trivalents with the chromosomes of the first two sets while the nonhomologous chromosomes form the univalents. This leads to disturbances in the distribution of the chromsomes in the first mitotic division and to the formation of gametes with variable chromosome number. It is likely that these forms are created as a result of hybridization of the diploid parthenogenetic form with a closely related bisexual diploid species. A similar situation is created in meiosis in the worms from Scandinavia (Clone VIII). Though there were no mitotic metaphases in the preparations, the presence in meiosis of plates with $n=25-$ 


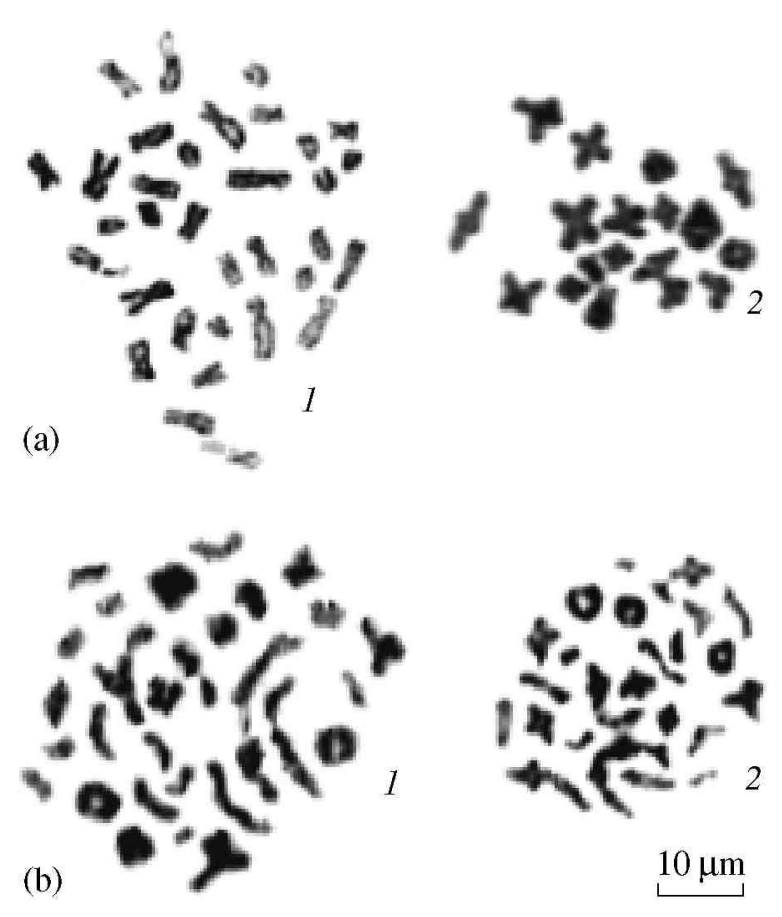

Fig. 3. Chromosomes of $A$. (superspecies) caliginosa: a - $1 \quad A$. caliginosa (Zhitomir), mitotic metaphase (1) and diaki-nesis (2); b diakineses $(1,2)$ A. trapezoides (Clone VIII) (Nikolaevka).

36 attests to the polyploidy of the individuals studied (3 specimens).

Thus, karyological investigation of the apomictic clonal forms demonstrates the triploid structure of these forms.

\section{DISCUSSION}

Diversity of clones. In view of the significant number of samples and the total volume of the subject matter (19 clones in 157 subject individuals) of A. trapezoides, it should be considered as a species characterized by genetic diversity that is moderate for parthenogenetic worms. In fact, the genus Ostolasium, the individual Lumbricidae of which are large in size, exhibit a far lower level of clonal diversity $[5,10]$ than those found in A. trapezoides in the present investigation. For example, in Fennoscandia the number of clones in O. Tyrtaeum amounted to 24 in a set of 238 individuals, while in $O$. cyaneus there were only 2 clones among 138 individuals. On the other hand, in small earthworms (the triploid Aporrectodea rosea [11], tetraploid Eiseniella teraedra [21], and Dendrodrilus rubinus [6], as well as the hexaploid Dendrobaena octaedra [9]), the level of clonal diversity was much higher, with each third or fourth individual constituting a new clone.
Origin of clones. An analysis of the electrophoretic spectra demonstrated that constant heterozygosity, which manifested itself in an increase in the number of fractions, was observed in most of the clonal forms. This phenomenon manifested itself most often at the loci of nonspecific esterases, the products of which were usually represented in the electrophoregrams by doubled fractions, more rarely by Aat and even more rarely by $M d h$, in the spectra of which they appeared as dimer proteins, in this case each containing three fractions. These results on biochemical gene marking as well as an analysis of the behavior of the chromosomes in meiosis that demonstrates their nonhomology, contradict the hypothesis of an autopolyploid origin of $A$. trapezoides [18].

Of particular interest is the fact that the allelic pools of the triploid clones of $A$. trapezoides are not reducible to the A. caliginosa gene pool, the habitat of which at present encompasses nearly the entire territory of Ukraine. Note that in most cases there are common alleles with respect to the two loci Aat and Mdh. However, for the locus $E s-4$ there are alleles that encode products with high electrophoretic mobility (Fig. 1) present among individual animals in the overwhelming majority of the clones; these alleles are absent in the amphimictic form. The only exceptions are Clones XI and XII from the north (Chernigov and Zhitormir regions) (Fig. 2a). Consequently, only the northern biotypes may possess a local origin, whereas all the southern clones either originated from a species related to $A$. caliginosa, the habitat of which is located more southerly, or there occurred substantial changes in the gene pools of the southern clones due to the triploid structure of the genome, which enables the accumulation of spontaneous mutations. In either case, we are entirely justified in supposing that the appearance of most clones of A. trapezoides in the fauna of Ukraine is the result of their settlement in dry steppe regions that are unfavorable for earthworms. Nevertheless, however, the opposite situation, that the clonal forms are aborigines of the steppe and that the amphimictic A. caliginosa is an invasive species, cannot be entirely ruled out, The trend toward a degree of synanthropization of $A$. caliginosa favors the latter hypothesis, since apomictic forms are mainly encountered in natural virgin landscapes.

Geography of amphimictic and apomictic forms. In the present study it has been shown that apomictic forms represented by the triploid A. trapezoides are dominant in the samples of earthworms from southern regions of Ukraine (Fig. 4). Such a trend conforms with the karyological data [2], according to which polyploidization of the genome of $A$. (superspecies) caliginosa occurs at the southern boundaries of its natural habitat. Moreover, a growth in the number and increase in the diversity of polyploid forms in the south is also of interest in view of the fact that it confirms a general trend that holds for other species of earthworms [22], according to which parthenogenetic forms are mark- 


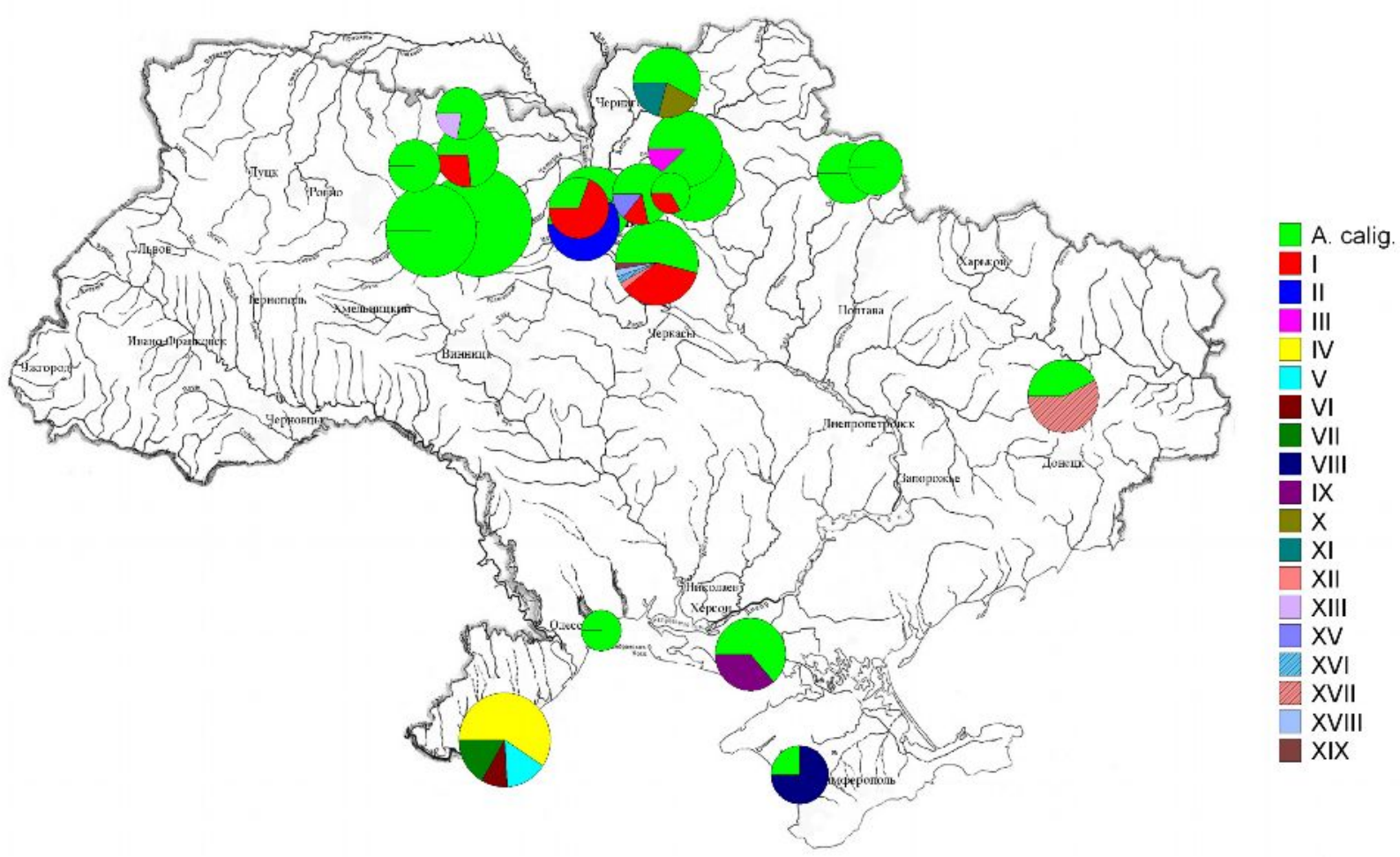

Fig. 4. Dispersal of clones of $A$. trapezoides and their representation in samples from the territory of Ukraine.

edly dominant at sites that are unfavorable for habitation, in particular, steppe conditions.

\section{CONCLUSION}

As a result of the present study, it has been demonstrated that two species complexes of earthworms exist in Ukraine, the amphimictic $A$. caliginosa, which is distributed throughout the country, and the apomictic $A$. trapezoides, which is represented in the study by 19 clones formed in hybridization of a series of species, which most likely does not include $A$. caliginosa, a species that now inhabits the territory of Ukraine. A clearcut confinement of the parthenogenetic forms to the southern steppe regions of Ukraine, which are unfavorable for Lumbricidae, was demonstrated.

\section{REFERENCES}

1. Perel', T.S., Rasprostranenie i zakonomernost' raspredeleniya dozhdevykh chervei fauny SSSR (Dispersion and Laws of Distribution of Earthworms in the USSR Fauna), Moscow: Nauka, 1979.

2. Viktorov, A.G., Diversity of Polyploid Strains in the Earthworm Family Lumbricidae, Usp. sovrem. biologii, 1993, vol. 113, issue 3, pp. 304-312.

3. Muldal, S., The Chromosomes of the Earthworms. 1. The Evolution of Polyploidy, Heredity, 1952, vol. 6, pp. $55-76$.

4. Malinina,T.V. and Perel', T.S., Characteristics of the Chromosomal Strains of Eisenia nordenskioldi (Oli- gochaeta, Lumbricidaea) Using Biochemical Markers, Dokl. Akad. Nauk SSSR, 1984, vol. 279, no. 5, pp. 12651269.

5. Jaenike, J., Parker, E.D., and Selander, R.K., Clonal Niche Structure in Parthogenetic Earthworm Octalasion tirtaeum, Amer. Natur., 1980, vol. 116, pp. 196-205.

6. Jaenike, J., Ausubel, S., and Grimaldi, D.A., On the Evolution of Clonal Diversity in Parthenogenetic Earthworms, Pedobiologia, 1982, vol. 23, no. 4, pp. 304-310.

7. Jaenike, J. and Selander, R.K., On the Coexistence of Ecologically Similar Clones of Parthenogenetic Earthworms, Oikos, 1985, vol. 44, pp. 512-514.

8. Coboli, Sbordoni, M., de Matthaeus, E., Omodeo, P., Bidoli, R., and Rodino, E., Allozyme Variation and Divergence Between Diploid and Triploid Populations of Allobophora calignosa (Lumbricidae: Oligochaeta), in On Earthworms, Bomvicini, A.M. et al., Eds., Modena: Mucchi, 1987, pp. 53-71.

9. Terhivuo, J. and Saura, A., Allozyme Variation in Parthogenetic Dendrobaena octaedra (Oligochaeta: Lumbricidae) Populations of Eastern Fennoscandia, Pedobiologia, 1990, vol. 34, no. 2, pp. 113-139.

10. Terhuvuo, J. and Saura, A., Clonal and Morphological Variation in Marginal Populations of Parthenogenetic Earthworms Octalasion tyrtaeum and O. cyaneus (Oligochaeta: Lumbricidae) from Eastern Fennoscandia, Boll. Zool, 1993, vol. 60, pp. 87-96.

11. Terhuvuo, J. and Saura, A., Genic and Morphological Variation of the Parthenogenetic Earthworm Aporrectodea rosea in southern Finland (Oligochaeta, Lumbricidae), Ann. Zool. Fenneci., 1993, vol. 30, pp. 215-224. 
12. Terhuvuo, J. and Saura, A., Clone Pool Structure and Morphometric Variation in Endogenic and Epigenic North-European Parthenogenetic Earthworms (Oligochaeta, Lumbricidae), Pedobiologia, 1996, vol. 40, pp. 226-239.

13. Terhuvuo, J., Lundqvist, E., and Saura, A., Clone Diversity of Eiseniella tetrahedra (Oligochaeta, Lumbricidae) Along Regulated and Free-Flowing Boreal Rivers, Ecography, 2002, vol. 25, pp. 714-720.

14. Terhuvuo, J. and Saura, A., Low Clonal Diversity in Octolasion cyaneus (Oligochaeta, Lumbricidae), Pedobiologia, 2003, vol 47, pp. 434-439.

15. Terhuvuo, J. and Saura, A., Diversity and Clonal Diversity of North-European Parthenogenetic Earthworms, Biol. Invasions, 2006, vol. 8, pp. 1205-1218.

16. Peacock, F.C., Bunting, S.L., and Queen, K.G., Serum Protein Electrophoresis in Acrilamyde Gel Patterns from Normal Human Subjects, Science, 1965, vol. 147, pp. 1451-1455.
17. Ford, R. and Hamerton, J.L., A Colchicines Hipotonic Citrate Squash Sequence for Mammalian Chromosomes, Stain Technol., 1956, vol. 31, no. 6, pp. 247-251.

18. Thiriot-Quievreux, C., Chromosome Studies in Pelagic Opistobranch Molluscs, Can. J. Zool., 1988, vol. 66, pp. 1460-1477.

19. Stille, B., Ochman, H., and Selander, R.K., Genetic Structure of Populations of the Earthworm Aporrectodea tuberculate, Oikos, 1980, vol. 34, pp. 195-201.

20. Stebbins, D.L., Dispersal and Nature of Polyploid Types, in Poliploidiya (Polyploidy), Moscow: Izd-vo Inostr. Lit., 1956, pp. 25-55.

21. Terhivuo, J. and Saura, A., Island Biogeography of a North European Parthenogenetic Earthworm: Fugitive Clones of Eiseniella tetrahedra (Sav.) (Lumbricidae), Pedobiologia, 1999, vol. 43, pp. 481-486.

22. Perel', T.S., Geographic Features of Reproduction of Earthworms of the Family Lumbricidae, Zh. obshch. biologii, 1982, vol. 43, no. 5, pp. 649-658. 